\title{
Uncovering potential differentially expressed miRNAs and targeted mRNAs in myocardial infarction based on integrating analysis
}

\author{
SHIAI WANG and NA CAO \\ Department of Cardiology, Jinan Jigang Hospital, Jinan, Shandong 250000, P.R. China
}

Received March 12, 2020; Accepted August 25, 2020

DOI: $10.3892 / \mathrm{mmr} .2020 .11517$

\begin{abstract}
Myocardial infarction (MI) is one of the leading causes of death globally. The aim of the present study was to find valuable microRNAs (miRNAs/miRs) and target mRNAs in order to contribute to our understanding of the pathology of MI. miRNA and mRNA data were downloaded for differential expression analysis. Then, a regulatory network between miRNAs and mRNAs was established, followed by function annotation of target mRNAs. Thirdly, prognosis and diagnostic analysis of differentially methylated target mRNAs were performed. Finally, an in vitro experiment was used to validate the expression of selected miRNAs and target mRNAs. A total of 19 differentially expressed miRNAs and 1,007 differentially expressed mRNAs were identified. Several regulatory interaction pairs between miRNA and mRNAs were identified, such as hsa-miR-142-2p-long-chain-fattyacid-CoA ligase 1 (ACSL1), hsa-miR-15a-3p-nicotinamide phosphoribosyltransferase (NAMPT), hsa-miR-33b-5p-regulator of G-protein signaling 2 (RGS2), hsa-miR-17-3p-Jun dimerization protein 2 (JDP2), hsa-miR-24-1-5p-aquaporin-9 (AQP9) and hsa-miR-34a-5p-STAT1/AKT3. Of note, it was demonstrated that ACSL1, NAMPT, RGS2, JDP2, AQP9, STAT1 and AKT3 had diagnostic and prognostic values for patients with MI. In addition, STAT1 was involved in the 'chemokine signaling pathway' and 'Jak-STAT signaling pathway'. AKT3 was involved in both the 'MAPK signaling pathway' and 'T cell receptor signaling pathway'. Reverse transcription-quantitative PCR validation of hsa-miR-142-3p, hsa-miR-15a-3p, hsa-miR-33b-5p, ACSL1, NAMPT, RGS2 and JDP2 expression was consistent with the bioinformatics analysis. In conclusion, the identified miRNAs and mRNAs may be involved in the pathology of MI.
\end{abstract}

Correspondence to: Dr Shiai Wang, Department of Cardiology, Jinan Jigang Hospital, 21 Gongye North Road, Licheng, Jinan, Shandong 250000, P.R. China

E-mail: wangshiai@163.com

Key words: myocardial infarction, differentially expressed microRNAs, differentially expressed mRNAs, diagnose, prognosis

\section{Introduction}

Myocardial infarction (MI) is the death of cardiomyocytes caused by obstruction of one or more arteries supplying the heart $(1,2)$. Clinically, patients with MI often show a number of different symptoms including pain, fever and increased white blood cell count (3). The pivotal pathological characteristic after MI is cardiac fibrosis, which leads to cardiac remodeling and failure $(4,5)$. In addition, there are various complications of MI, such as arrhythmia, pericarditis, heart rupture and papillary muscle rupture (6). MI pathology can also be complicated by cardiogenic shock, which can be life threatening (7). The recurrence rate of $\mathrm{MI}$ is high, and the time of recurrence is the highest within two years after remission. Moreover, each relapse can aggravate the disease (8).

The pathological mechanism of MI is complex. Frangogiannis et al (9) and Nian et al (10) found that MI was related to innate immunity programming, which is crucial in cardiac remodeling. Angiogenesis is also a key event for re-establishing the blood supply to the surviving myocardium following MI, which contributes to recovery of cardiac function (11). In addition, age, sex, smoking status, hypertension, atherosclerosis, dyslipidemia, diabetes mellitus and hypercholesterolemia are reported to be the primary risks of MI $(12,13)$.

MicroRNAs (miRNAs/miRs) can negatively regulate target mRNA expression. Previous reports demonstrated that miRNAs could be crucial regulators in cardiovascular diseases, including hypertrophy, heart failure and ischemic cardiomyopathy (14-17). It is worth noting that some miRNAs, such as hsa-miR-1, hsa-miR-21, hsa-miR-206 and hsa-miR-499-5p, are significantly dysregulated in the hearts of patients with acute MI (18-22). In view of the important roles of miRNAs in MI, the aim of the present study was to find potential miRNAs and target mRNAs in MI, which may be useful in understanding the molecular mechanism of MI pathology. The present findings demonstrated that the epigenetic modifications of hsa-miR-142-2p-ACSL1, hsa-miR-15a-3p-NAMPT, hsa-miR-17-3p-JDP2, hsa-miR-33-5p-RGS2, hsa-miR24-1-5p-AQP9 and hsa-miR-34a-5p-STAT1/AKT3 and four signaling pathways ('chemokine signaling pathway', 'Jak-STAT signaling pathway', 'MAPK signaling pathway' and ' $T$ cell receptor signaling pathway') may be associated with the development of MI. In addition, ACSL1, NAMPT, 
RGS2, JDP2, AQP9, STAT1 and AKT3 could help monitor the recurrence risk of patients with MI.

\section{Materials and methods}

Data retrieval. The miRNA and mRNA expression profiles were downloaded from the Gene Expression Omnibus (GEO) database (http://www.ncbi.nlm.nih.gov/geo). The key words of 'Myocardial infarction' and 'Homo sapiens' was used to search for related datasets. Screening requirements for the included datasets were as follows: i) The selected datasets must be genome-wide miRNA/mRNA transcriptome expression data; and ii) both standardized and original datasets were considered in this study. According to the aforementioned screening criteria, one miRNA dataset (GSE24548) and four mRNA datasets (GSE97320, GSE24519, GSE66360 and GSE60993) were selected for integrated analysis, which is listed in Table I.

Identification of differentially expressed miRNAs and mRNAs. Firstly, scale standardization was performed for all datasets. The limma (version 3.36.5) (23) and metaMA (version 3.1.2) (24) packages in $\mathrm{R}$ were then used to identify differentially expressed miRNAs and mRNAs. The inverse normal method was used to combine the P-value in metaMA. The false discovery rate (FDR) was performed for multiple testing corrections of raw P-values through the Benjamin and Hochberg method $(25,26)$. The threshold of differentially expressed miRNAs and mRNAs was set as FDR $<0.01$ and FDR $<0.05$, respectively. The pheatmap $\mathrm{R}$ package (cran.r-project.org/web/packages/pheatmap/index.html) was used for hierarchical clustering analysis of the differentially expressed miRNAs and mRNAs (27).

Correlation analysis between differentially expressed miRNAs and mRNAs. The miRWalk3.0 (http://mirwalk.umm. uni-heidelberg.de/) software was used to predict the differentially expressed target mRNAs of differentially expressed miRNAs. The establishment of a miRNA-mRNA regulatory network was visualized using Cytoscape 3.7.1 software (28).

Functional analysis of differentially expressed mRNAs. Gene Ontology (GO) $(29,30)$ and the Kyoto Encyclopedia of Genes and Genomes (KEGG) (31) pathway enrichment via GeneCodis 3 (http://genecodis.cnb.csic.es) software were used to analyze the biological functions of the differentially expressed target mRNAs of differentially expressed miRNAs. The criterion for selecting significantly enriched functional terms of target differentially expressed mRNAs was $\mathrm{P}<0.05$.

Screening of differentially expressed target mRNAs associated with MI prognosis. In the process of screening for datasets that contained miRNA and mRNA expression profiles, the GSE59867, GSE97320, GSE24519, GSE66360 and GSE60993 datasets were initially retrieved. As the GSE59867 dataset recorded the mRNA expression profile in the blood of patients at admission (111 cases), at discharge (101 cases), one month after discharge ( 95 cases) and six months after discharge ( 83 cases), this dataset was used for screening mRNAs associated with prognosis from identified targeted differentially expressed mRNAs, with the aim of finding reliable biomarkers to monitor the risk of recurrence in patients with MI.

Diagnostic analysis of differentially expressed target $m R N A s$ associated with prognosis. In order to study whether identified differentially expressed target mRNAs associated with prognosis have diagnostic value, receiver operating characteristic (ROC) analysis was performed using pROC package in $\mathrm{R}$ language (32). The area under the curve (AUC) under binomial exact confidence interval was calculated and the ROC curve was generated.

In vitro validation of key miRNAs and target mRNAs. A total of five patients with MI and five normal controls were enrolled from October to November 2019 at Jinan Jigang Hospital. The inclusion criteria of patients with MI was as follows: i) Time of chest pain or distress was $>30$ min within $24 \mathrm{~h}$, and the levels of creatine kinase-MB and troponin $\mathrm{T}$ were higher than the normal range; ii) no history of MI; iii) no drug treatment or surgical treatment before admission; iv) patients had to provide blood samples before hospitalization, at discharge and 6 months after MI; and v) patients had to provide complete clinical data, including sex, age, height and weight. The exclusion criteria was as follows: i) Patients with myocarditis and other diseases caused by chest pain or distress; ii) patients had a history of renal failure, advanced liver disease, malignant tumor and other inflammatory diseases, such as psoriasis and rheumatoid arthritis; iii) patients with recurring MI; iv) patients with incomplete clinical data; and v) patients who did not provide blood samples before hospitalization, at discharge and 6 months after MI. Ethical approval was obtained from the Ethics Committee of Jinan Jigang Hospital (approval no. JG-001) and informed written consent was obtained from all individuals.

Total RNA from the blood samples was extracted using the RNAliquid reagent (Tiangen Biotech Co., Ltd.), according to the manufacturer's protocols. RNA $(1 \mu \mathrm{g})$ was applied to synthesize cDNA for $3 \mathrm{~min}$ at $42^{\circ} \mathrm{C}$, followed by $15 \mathrm{~min}$ at $42^{\circ} \mathrm{C}$ and $3 \mathrm{~min}$ at $95^{\circ} \mathrm{C}$ using FastQuant RT kit (Tiangen Biotech Co., Ltd.). Then, reverse transcription-quantitative PCR (RT-qPCR) was performed in an ABI 7300 Real-time PCR system with SYBR-Green PCR Master Mix (Applied Biosystems; Thermo Fisher Scientific, Inc.). The thermocycling conditions consisted of: i) Initial denaturation of $15 \mathrm{~min}$ at $95^{\circ} \mathrm{C}$; iii) 40 cycles of $10 \mathrm{sec}$ at $95^{\circ} \mathrm{C}, 30 \mathrm{sec}$ at $55^{\circ} \mathrm{C}, 32 \mathrm{sec}$ at $72^{\circ} \mathrm{C}$; and iii) $15 \mathrm{sec}$ at $95^{\circ} \mathrm{C}, 60 \mathrm{sec}$ at $60^{\circ} \mathrm{C}$, then $15 \mathrm{sec}$ at $95^{\circ} \mathrm{C}$. All reactions were carried out in triplicate $\beta$-actin and GAPDH were used as the internal reference genes. Relative gene expression was analyzed by the fold-change method (33).The sequences of reverse and forward primers for all of the genes analyzed were as follows: i) ACSL1-forward, 5'-TGTGGGACCGGCTGA TCTT-3'; ii) ACSL1-reverse, 5'-AGTGCACTCTGTCTGTCC GT-3'; iii) NAMPT-forward, 5'-TCTTCTGAGGCAGCGGTT G-3'; iv) NAMPT-reverse, 5'-GGCTGGAGTAGTGGGAAA GC-3'; v) RGS2-forward, 5'-AAGATTGGAAGACCCGTT TGAG-3'; vi) RGS2-reverse, 5'-GCAAGACCATATTTGCTG GCT-3'; vii) JDP2-forward, 5'-AGACCCAGATTGAGGAGC TG-3'; JDP2-reverse, 5'-AGTGGGTTGCCTTCTGACCTC-3'; viii) hsa-miR-142-3p-forward, 5'-TGTAGTGTTTCCTACTTT 
Table I. One miRNA dataset and four mRNA datasets used for integrated analysis.

\begin{tabular}{|c|c|c|c|c|c|c|}
\hline First author, year & GEO ID & Platform & Samples & Type & Omics & (Refs.) \\
\hline Bellin et al, 2017 & GSE24548 & GPL 8227 & MI:Control, 4:3 & Blood & miRNA & Unpublished \\
\hline Fan et al, 2017 & GSE97320 & GPL 570 & MI:Control, 3:3 & Blood & mRNA & (84) \\
\hline Bellin et al, 2017 & GSE24519 & GPL 2895 & MI:Control, 34:4 & Blood & mRNA & Unpublished \\
\hline Muse et al, 2015 & GSE66360 & GPL 570 & MI:Control, 49:50 & Blood & mRNA & $(85)$ \\
\hline Park et al, 2015 & GSE60993 & GPL6884 & MI:Control, 17:7 & Blood & mRNA & (86) \\
\hline
\end{tabular}

MI, myocardial infarction; GEO, Gene Expression Omnibus; miRNA, microRNA.

Table II. Differentially expressed miRNAs in MI.

\begin{tabular}{|c|c|c|c|c|}
\hline Symbol & $\operatorname{LogFC}$ & Average expression & P-value & FDR \\
\hline hsa-miR-32-5p & -1.72 & 4.66 & $3.17 \times 10^{-05}$ & $4.93 \times 10^{-03}$ \\
\hline hsa-miR-545-3p & -1.50 & 4.37 & $3.76 \times 10^{-05}$ & $4.93 \times 10^{-03}$ \\
\hline hsa-miR-219a-5p & -1.34 & 3.30 & $5.23 \times 10^{-05}$ & $4.93 \times 10^{-03}$ \\
\hline hsa-miR-29b-3p & -1.46 & 7.45 & $1.04 \times 10^{-04}$ & $6.01 \times 10^{-03}$ \\
\hline hsa-miR-548a-5p & -1.05 & 2.59 & $1.11 \times 10^{-04}$ & $6.04 \times 10^{-03}$ \\
\hline hsa-miR-17-3p & -1.04 & 6.45 & $2.03 \times 10^{-04}$ & $6.04 \times 10^{-03}$ \\
\hline hsa-miR-33a-5p & -1.34 & 6.14 & $2.05 \times 10^{-04}$ & $6.04 \times 10^{-03}$ \\
\hline hsa-miR-33b-5p & -1.17 & 2.70 & $2.14 \times 10^{-04}$ & $6.04 \times 10^{-03}$ \\
\hline hsa-miR-186-3p & -0.90 & 2.14 & $2.32 \times 10^{-04}$ & $6.04 \times 10^{-03}$ \\
\hline hsa-miR-101-3p & -1.19 & 7.41 & $2.46 \times 10^{-04}$ & $6.04 \times 10^{-03}$ \\
\hline hsa-miR-142-3p & -1.08 & 1.05 & $2.57 \times 10^{-04}$ & $6.04 \times 10^{-03}$ \\
\hline hsa-miR-598-3p & -1.14 & 4.69 & $2.84 \times 10^{-04}$ & $6.04 \times 10^{-03}$ \\
\hline hsa-miR-362-3p & -1.51 & 3.30 & $2.91 \times 10^{-04}$ & $6.04 \times 10^{-03}$ \\
\hline hsa-miR-590-5p & -1.20 & 7.49 & $3.10 \times 10^{-04}$ & $6.04 \times 10^{-03}$ \\
\hline hsa-miR-24-1-5p & -1.07 & 5.30 & $3.20 \times 10^{-04}$ & $6.04 \times 10^{-03}$ \\
\hline hsa-miR-34a-5p & 1.10 & 4.99 & $5.55 \times 10^{-04}$ & $9.75 \times 10^{-03}$ \\
\hline hsa-miR-15a-3p & -0.84 & 2.89 & $5.86 \times 10^{-04}$ & $9.75 \times 10^{-03}$ \\
\hline hsa-miR-301a-3p & -0.91 & 7.82 & $6.47 \times 10^{-04}$ & $9.90 \times 10^{-03}$ \\
\hline hsa-miR-19a-3p & -1.06 & 8.77 & $6.65 \times 10^{-04}$ & $9.90 \times 10^{-03}$ \\
\hline
\end{tabular}

$\operatorname{LogFC}>1$ and $\log F C<1$ represents upregulation and downregulation, respectively. LogFC, log fold-change; FDR, false discovery rate; miRNA, microRNA; MI, myocardial infarction.

ATGGA-3; ix) hsa-miR-15a-3p-forward, 5'-CAGGCCATATTG TGCTGCCTCA-3; x) hsa-miR-33b-3p-forward, 5'-GTGCAT TGCTGTTGCATTGC-3; xi) GAPDH-forward, 5'-GGAGCG AGATCCCTCCAAAAT-3'; xii) GAPDH-reverse, 5'-GGCTGT TGTCATACTTCTCATGG-3'; xiii) ACTB-forward, 5'-CAT GTACGTTGCTATCCAGGC-3'; and vix) ACTB-reverse, 5'-CTCCTTAATGTCACGCACGAT-3'. The sequences of the reverse primers for hsa-miR-142-3p, hsa-miR-15a-3p and hsa-miR-33b-3p were not disclosed by the manufacturer.

Statistical analysis. All statistical analyses were performed using GraphPad Prism (version 2.0; GraphPad Software, Inc.). For the result described in Figs. 7 and 9, one-way ANOVA, followed by Bonferroni correction, were used to assess statistical significance among different groups. Results are presented as the mean \pm SD. All experiments were repeated independently at least three times. $\mathrm{P}<0.05$ was considered to indicate a statistically significant difference.

\section{Results}

Expression pattern of miRNA and mRNA. A total of 19 differentially expressed (one upregulated and 18 downregulated) miRNAs and 1,007 differentially expressed (287 upregulated and 720 downregulated) mRNAs were identified in MI. All differentially expressed miRNAs and the top 20 differentially expressed mRNAs are shown in Tables II and III, respectively. The heat map of all differentially expressed miRNAs and the top 100 differentially expressed mRNAs are shown in Figs. 1 and 2, respectively. 
Table III. Top 20 differentially expressed mRNAs in MI.

\begin{tabular}{|c|c|c|c|c|}
\hline Symbol & Combined ES & P-value & FDR & Up/down \\
\hline ACSL1 & 1.59 & $<4.44 \times 10^{-15}$ & $<6.76 \times 10^{-12}$ & Up \\
\hline S100A12 & 1.44 & $<4.44 \times 10^{-15}$ & $<6.76 \times 10^{-12}$ & Up \\
\hline IL1R2 & 1.27 & $4.44 \times 10^{-15}$ & $6.76 \times 10^{-12}$ & Up \\
\hline NAMPT & 1.24 & $1.22 \times 10^{-14}$ & $1.69 \times 10^{-11}$ & Up \\
\hline RGS2 & 1.60 & $2.51 \times 10^{-14}$ & $3.18 \times 10^{-11}$ & Up \\
\hline AQP9 & 1.19 & $3.22 \times 10^{-14}$ & $3.77 \times 10^{-11}$ & Up \\
\hline JDP2 & 1.20 & $4.13 \times 10^{-14}$ & $4.49 \times 10^{-11}$ & Up \\
\hline DUSP1 & 1.24 & $2.57 \times 10^{-13}$ & $2.17 \times 10^{-10}$ & Up \\
\hline HAL & 1.12 & $5.64 \times 10^{-13}$ & $4.30 \times 10^{-10}$ & Up \\
\hline S100A8 & 1.88 & $6.36 \times 10^{-13}$ & $4.61 \times 10^{-10}$ & Up \\
\hline PLA2G12A & -1.34 & $2.09 \times 10^{-13}$ & $1.87 \times 10^{-10}$ & Down \\
\hline GIMAP6 & -1.08 & $1.55 \times 10^{-12}$ & $9.43 \times 10^{-10}$ & Down \\
\hline PAQR8 & -1.32 & $1.85 \times 10^{-12}$ & $1.08 \times 10^{-09}$ & Down \\
\hline CHST12 & -1.17 & $1.67 \times 10^{-11}$ & $7.83 \times 10^{-09}$ & Down \\
\hline GZMA & -1.03 & $3.45 \times 10^{-11}$ & $1.31 \times 10^{-08}$ & Down \\
\hline RNASEH2B & -1.20 & $4.46 \times 10^{-11}$ & $1.61 \times 10^{-08}$ & Down \\
\hline DENND2D & -1.03 & $4.95 \times 10^{-11}$ & $1.71 \times 10^{-08}$ & Down \\
\hline RPAP2 & -1.12 & $8.16 \times 10^{-11}$ & $2.53 \times 10^{-08}$ & Down \\
\hline GIMAP7 & -1.00 & $1.33 \times 10^{-10}$ & $3.76 \times 10^{-08}$ & Down \\
\hline TRIM68 & -1.04 & $2.13 \times 10^{-10}$ & $5.68 \times 10^{-08}$ & Down \\
\hline
\end{tabular}

ES, effect size; FDR, false discovery rate; MI, myocardial infarction.

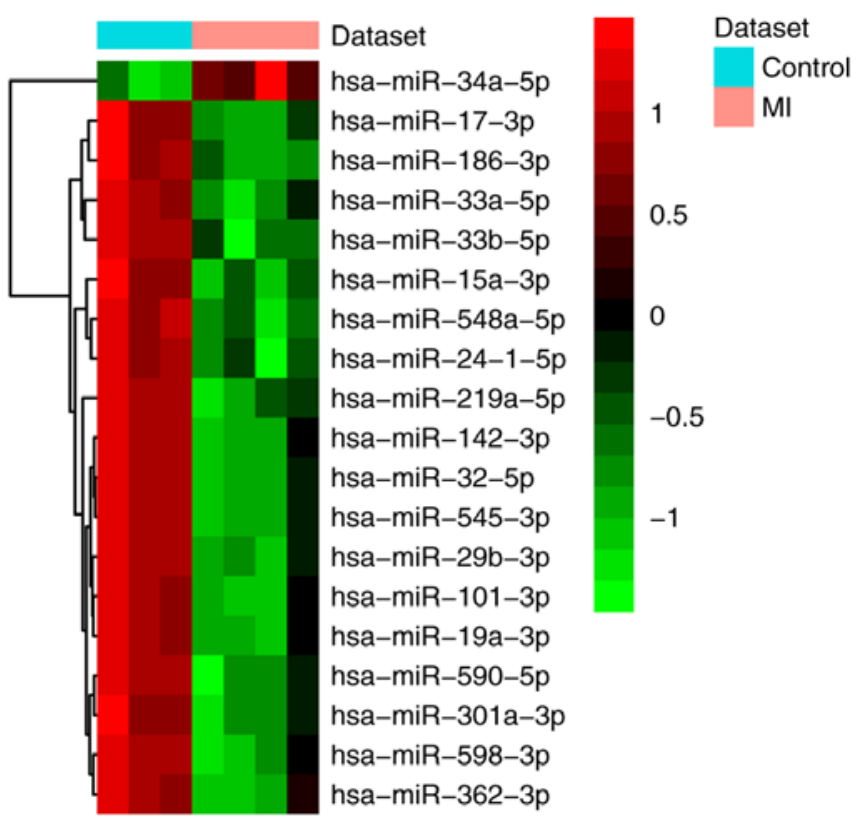

Figure 1. Heat map of all differentially expressed miRNAs in MI. The differentially expressed miRNA clustering tree is shown on the right. Red, below the reference channel; green, higher than the reference. miRNA/miR, microRNA; MI, myocardial infarction.

Associations between miRNAs and mRNAs. Depending on the target analysis, 2,137 miRNA-mRNA pairs, including 19 miRNAs and 481 mRNAs, were identified. The regulatory network of miRNA-mRNA is shown in Fig. 3. In addition, the regulatory subnetworks of miRNAs-mRNAs between hsa-miR-142-3p, hsa-miR-15a-3p, hsa-miR-17-3p, hsa-miR-33b-5p, hsa-miR-24-1-5p, hsa-miR-34a-5p and their target mRNAs are shown in Fig. 4.

Functional analysis of differentially expressed target $m R N A s$. In order to understand the biological function of 481 differentially expressed target mRNAs of 19 differentially expressed miRNAs, GO and KEGG pathway analysis were performed. The top 5 significantly enriched GO terms and top 12 KEGG terms are shown in Figs. 5 and 6, respectively. The biological process, cell component and molecular function 'regulation of transcription, DNA dependent', 'nucleus' and protein binding' were significantly enriched, respectively (Fig. 5). For KEGG terms, it was found that STAT1 was involved in the 'chemokine signaling pathway' and 'Jak-STAT signaling pathway'. In addition, AKT3 was involved in the 'MAPK signaling pathway' and ' $T$ cell receptor signaling pathway' (Fig. 6).

Identification of differentially expressed target mRNAs associated with prognosis. Through comparative analysis between mRNAs in the GSE59867 dataset and identified 481 differentially expressed target mRNAs, it was found that 185 differentially expressed target mRNAs, including long-chain-fatty-acid-CoA ligase 1 (ACSL1), nicotinamide phosphoribosyltransferase (NAMPT), regulator of G-protein signaling 2 (RGS2), Jun dimerization protein 2 (JDP2), aquaporin-9 (AQP9), STAT1 and AKT3, were associated with prognosis. The expression levels of ACSL1, NAMPT, RGS2, 


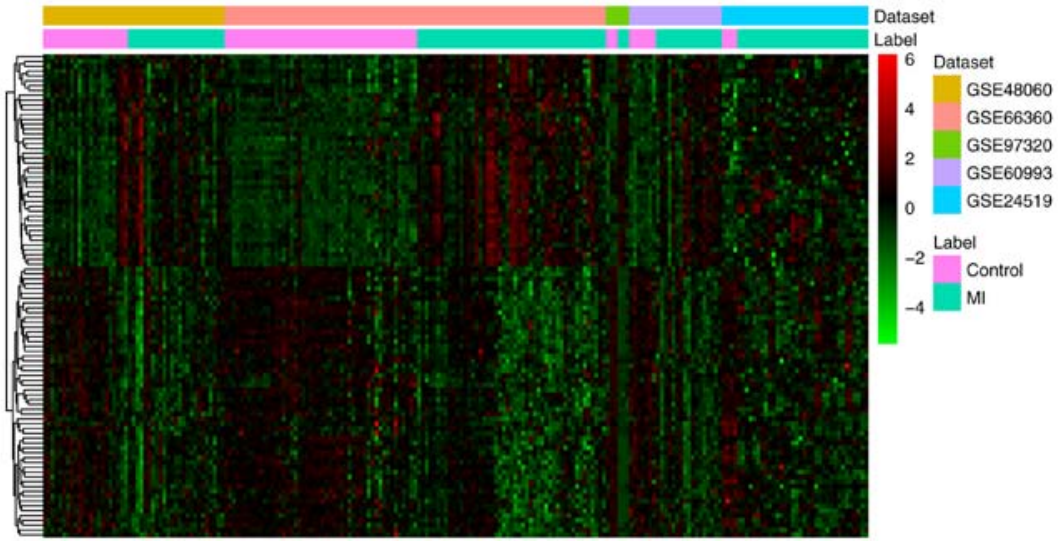

Figure 2. Heat map of top 100 differentially expressed mRNAs in MI. The differentially expressed mRNA clustering tree is shown on the right. Red, below the reference channel; green, higher than the reference. MI, myocardial infarction.

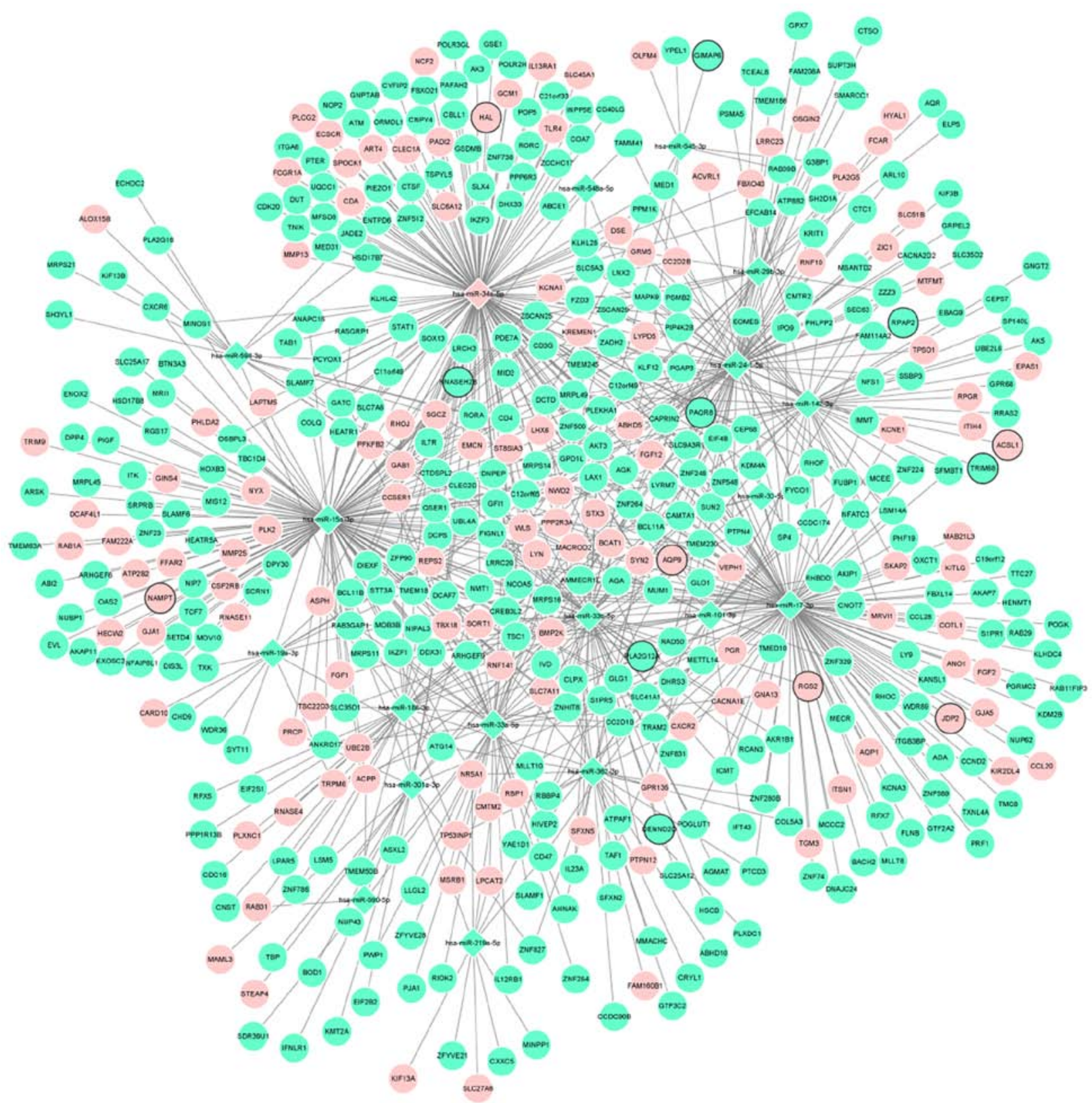

Figure 3. Regulatory network of miRNA-mRNAs between 19 differentially expressed miRNAs and 481 differentially expressed mRNAs in myocardial infarction. The rhombuses and circles represent the differentially expressed miRNAs and the differentially expressed target mRNAs, respectively. The red and blue color represent upregulation and downregulation, respectively. The black borders represent the top 10 up- and downregulated mRNAs. miRNA/miR, microRNA. 


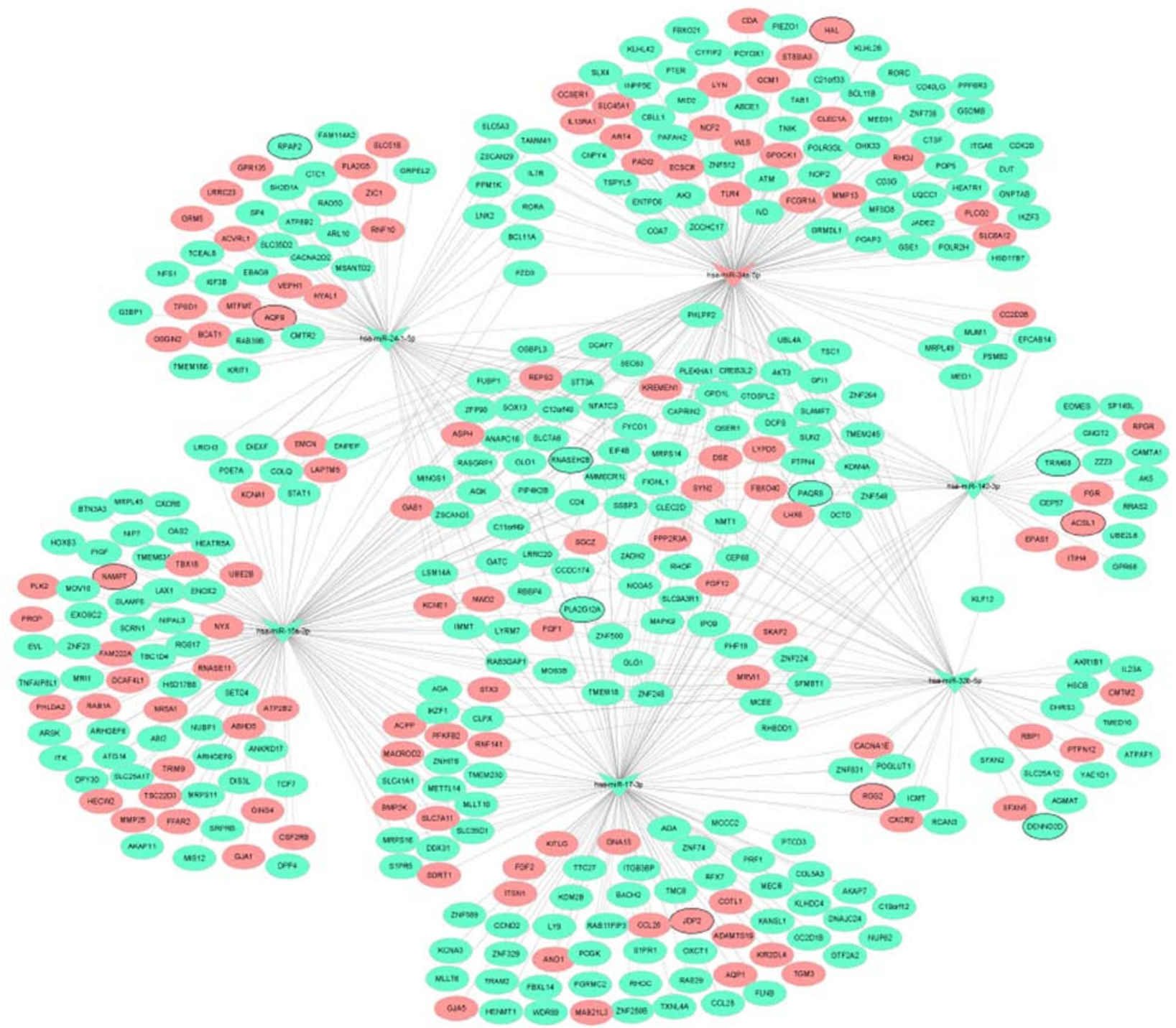

Figure 4. Regulatory subnetworks of miRNAs-mRNAs between hsa-miR-142-3p, hsa-miR-15a-3p, hsa-miR-17-3p, hsa-miR-33b-5p, hsa-miR-24-1-5p, hsa-miR-34a-5p and their target mRNAs in myocardial infarction. The triangles and circles represent the differentially expressed miRNAs and differentially expressed target mRNAs, respectively. The red and green color represent upregulation and downregulation, respectively. The black borders represents the top 10 up- and downregulated mRNAs. miRNA/miR, microRNA.

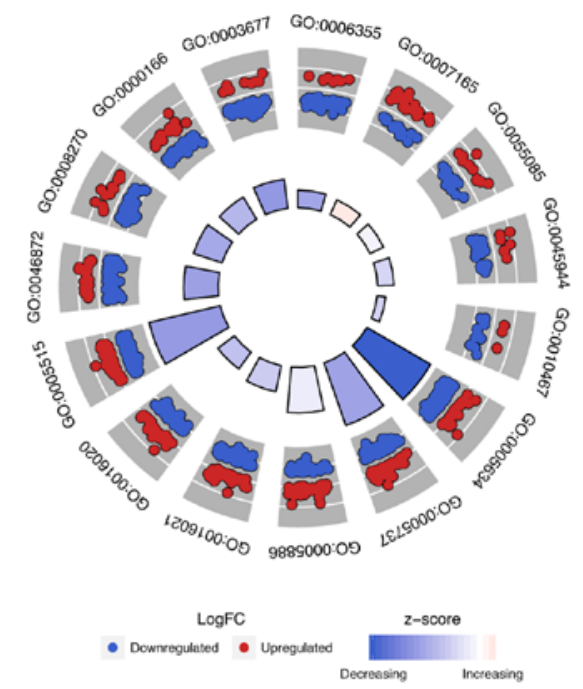

\begin{tabular}{|c|c|}
\hline ID & Description \\
\hline GO:0006355 & Regulation of transcription, DNA-dependent (BP) \\
\hline GO:0007165 & Signal transduction (BP) \\
\hline GO:0055085 & Transmembrane transport (BP) \\
\hline GO:0045944 & Positive regulation of transcription from RNA polymerase II promoter (BP) \\
\hline GO:0010467 & Gene expression (BP) \\
\hline GO:0005634 & Nucleus (CC) \\
\hline GO:0005737 & Cytoplasm (CC) \\
\hline GO:0005886 & Plasma membrane (CC) \\
\hline GO:0016021 & Integral to membrane (CC) \\
\hline GO:0016020 & Membrane (CC) \\
\hline GO:0005515 & Protein binding (MF) \\
\hline GO:0046872 & Metal ion binding (MF) \\
\hline GO:0008270 & Zinc ion binding (MF) \\
\hline GO:0000166 & Nucleotide binding (MF) \\
\hline GO:0003677 & DNA binding (MF) \\
\hline
\end{tabular}

Figure 5. Top 5 significant enrichment GO terms of the differentially expressed target mRNAs in myocardial infarction. The z-score clustering in the GO terms of the differentially expressed target mRNAs is shown at the bottom. The red and blue color represent upregulated and downregulated mRNAs, respectively. BP, biological process; CC, cellular component; MF, molecular function; GO, Gene Ontology. 


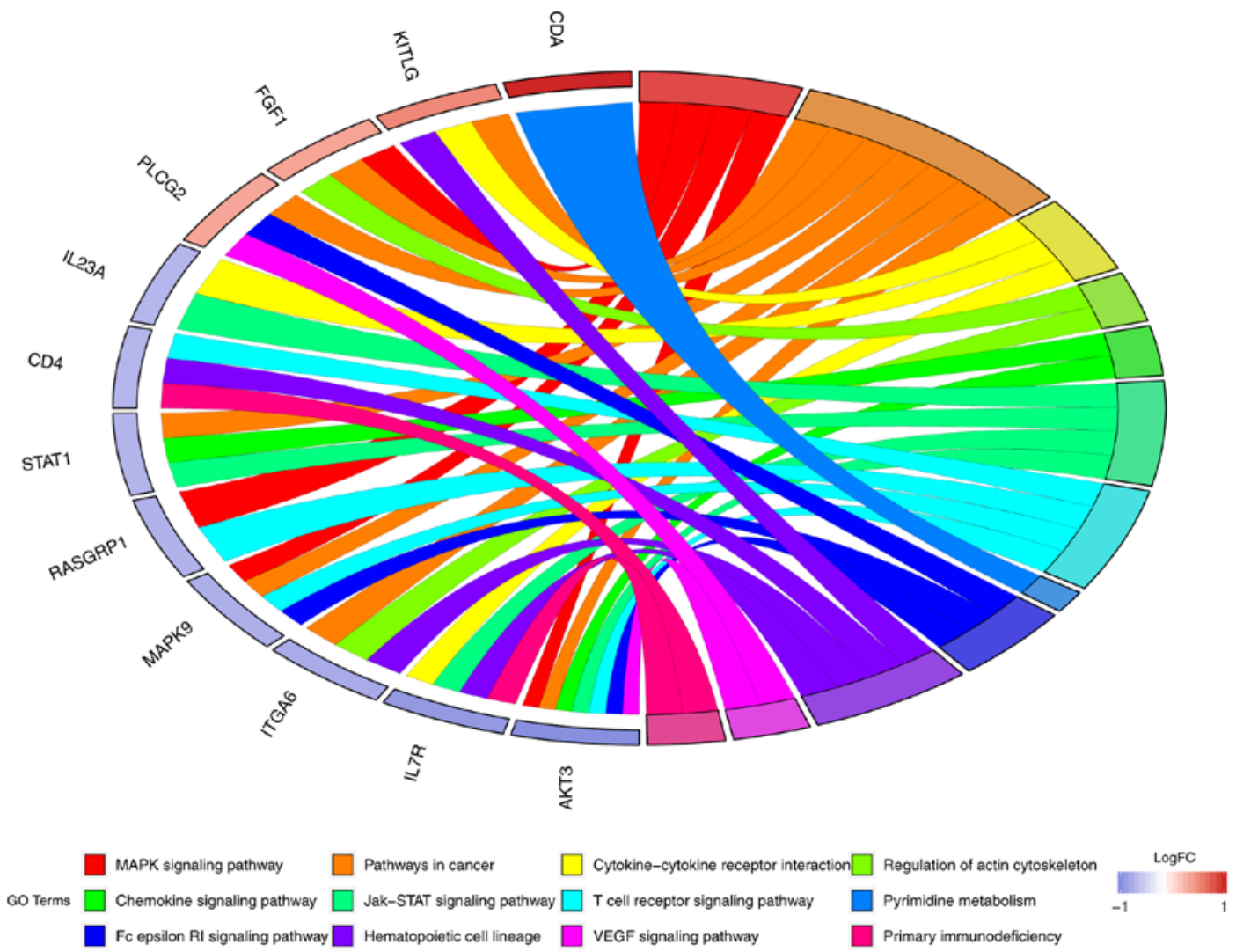

Figure 6. Top 12 Kyoto Encyclopedia of Genes and Genomes signaling pathways of the differentially expressed target mRNAs in myocardial infarction.
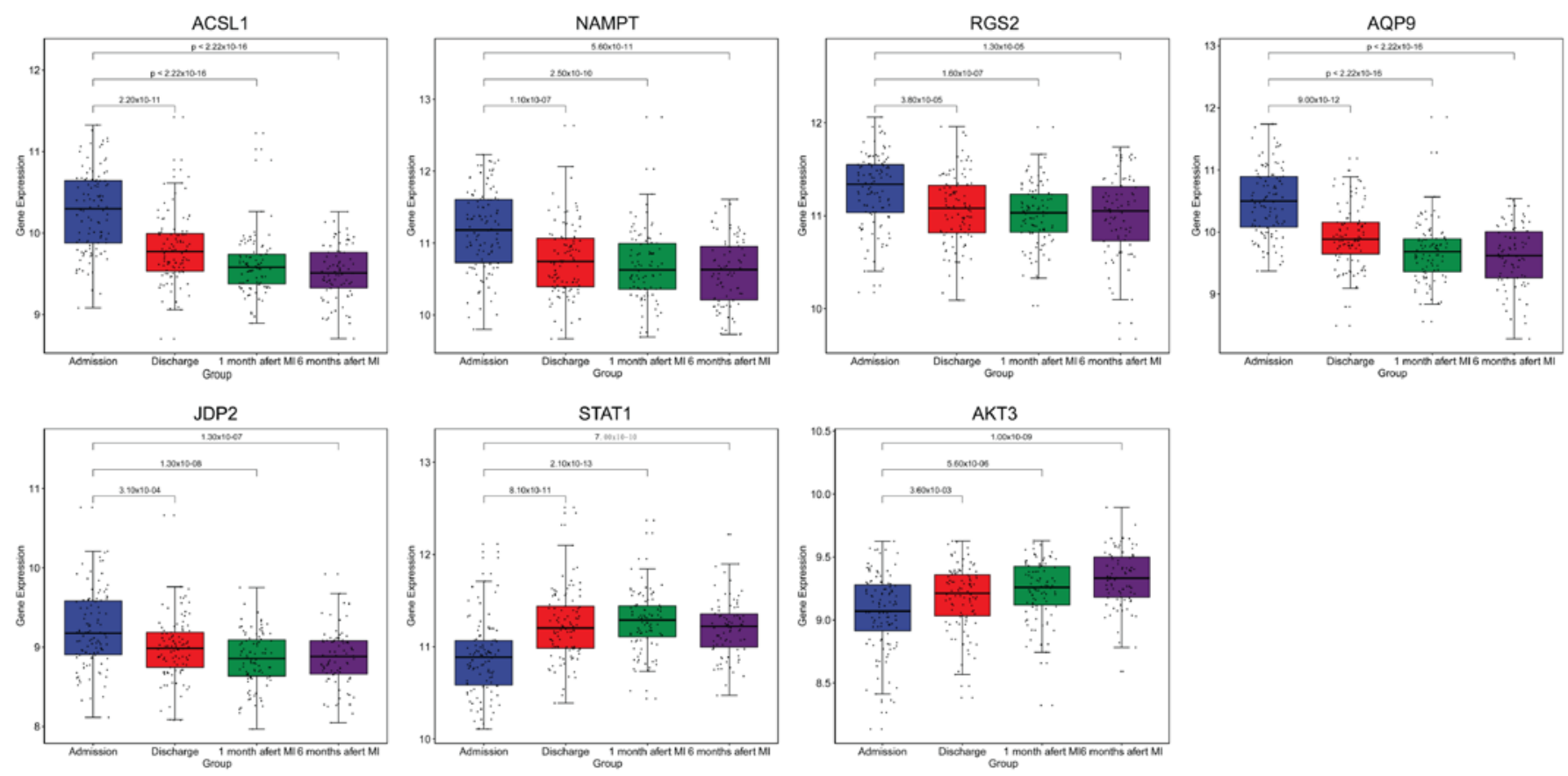

Figure 7. Box plots of ACSL1, NAMPT, RGS2, AQP9, JDP2, STAT1 and AKT3 expression. The expression levels of ACSL1, NAMPT, RGS2, AQP9, JDP2, STAT1 and AKT3 were determined in the blood of patients with MI at admission $(\mathrm{n}=111)$, at discharge $(\mathrm{n}=101), 1$ month after discharge $(\mathrm{n}=95)$ and 6 months after discharge $(\mathrm{n}=83)$. ACSL1, long-chain-fatty-acid-CoA ligase 1; NAMPT, nicotinamide phosphoribosyltransferase; RGS2, regulator of G-protein signaling 2; JDP2, Jun dimerization protein 2; AQP9, aquaporin-9; MI, myocardial infarction.

AQP9, JDP2, STAT1 and AKT3 were measured in the blood of patients with MI at admission, discharge, one month after discharge and six months after discharge (Fig. 7). The results showed that the expression levels of ACSL1 $\left(\mathrm{P}=2.2 \times 10^{-11}\right.$; $\left.\mathrm{P}<2.22 \times 10^{-16} ; \mathrm{P}<2.22 \times 10^{-16}\right)$, NAMPT $\left(\mathrm{P}=1.1 \times 10^{-07}\right.$; $\left.\mathrm{P}=2.5 \times 10^{-10} ; \mathrm{P}=5.6 \times 10^{-11}\right), \operatorname{RGS} 2\left(\mathrm{P}=3.8 \times 10^{-05} ; \mathrm{P}=1.6 \times 10^{-07}\right.$; 

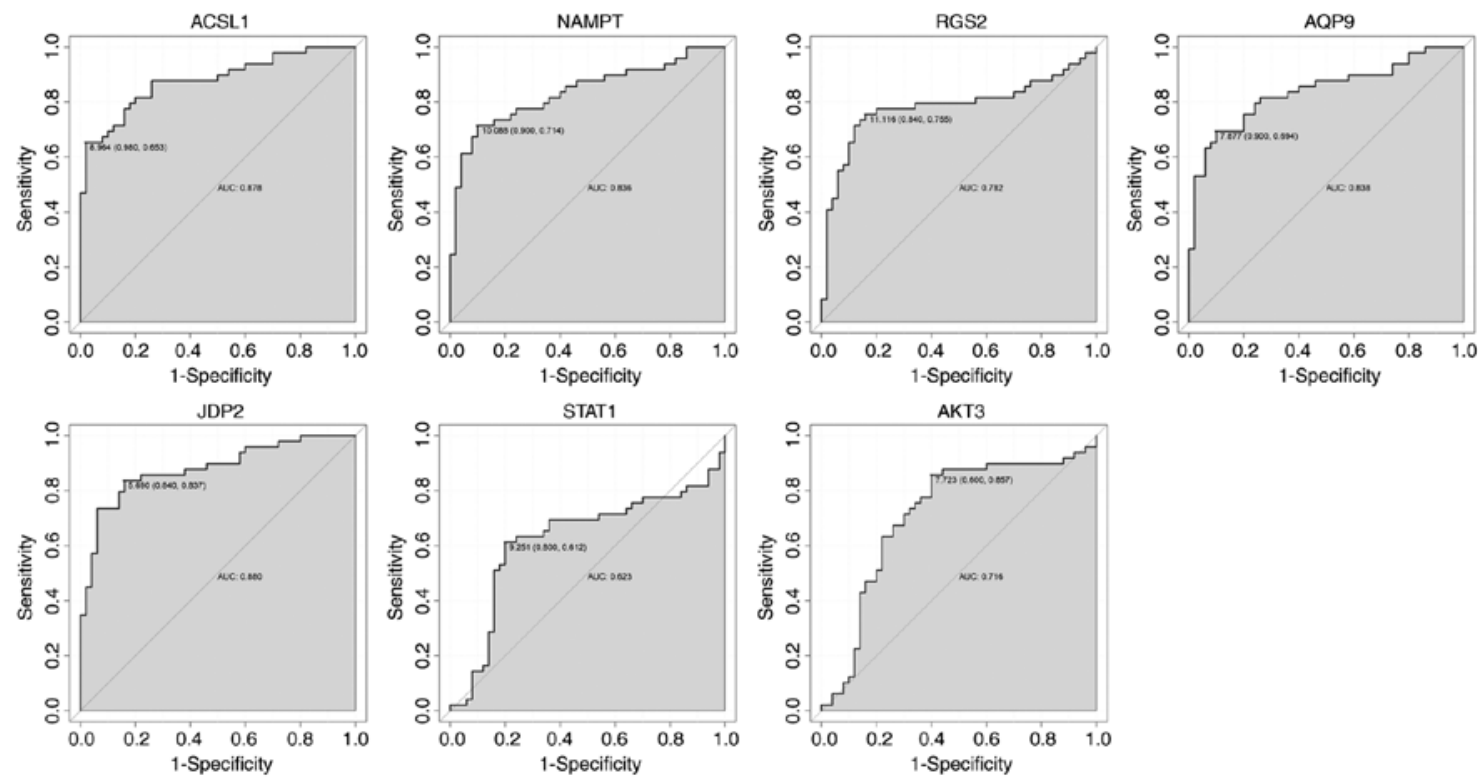

Figure 8. ROC curves of ACSL1, NAMPT, RGS2, AQP9, JDP2, STAT1 and AKT3 expression in myocardial infarction. The ROC curves were used to show the diagnostic value of these genes with 1-specificity and sensitivity. ACSL1, long-chain-fatty-acid-CoA ligase 1; NAMPT, nicotinamide phosphoribosyltransferase; RGS2, regulator of G-protein signaling 2; JDP2, Jun dimerization protein 2; AQP9, aquaporin-9; ROC, receiver operating characteristic; AUC, area under curve.

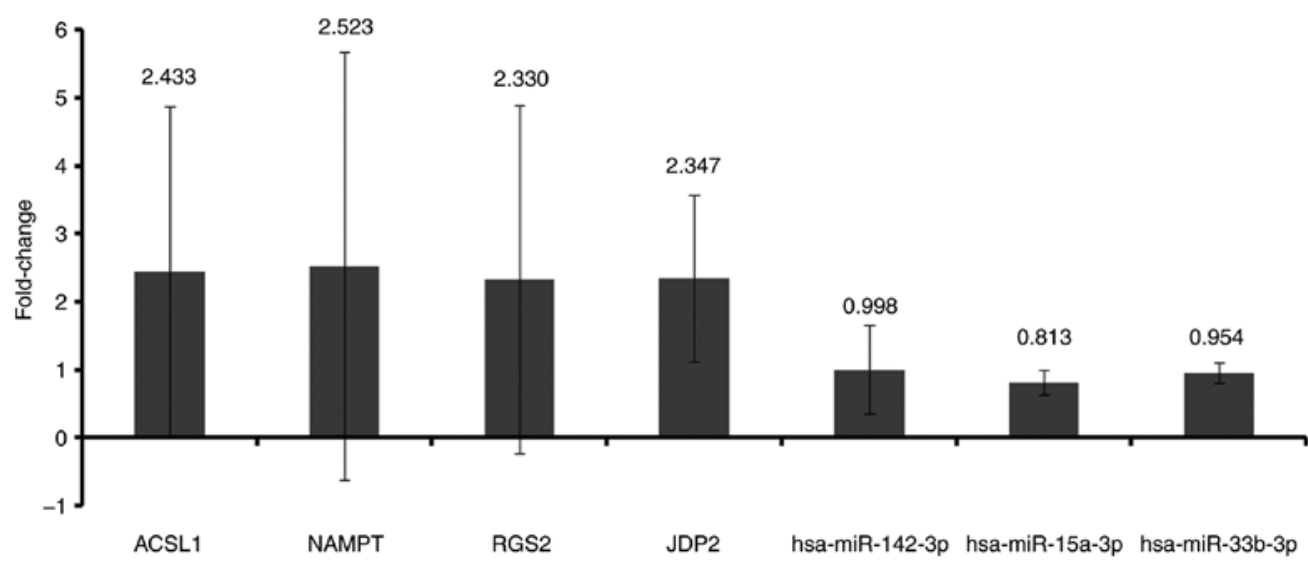

Figure 9. In vitro reverse transcription-quantitative PCR validation of differentially expressed miRNAs and their target mRNAs. One-way ANOVA, followed by Bonferroni correction, were used to assess statistical significance among different groups. Data are presented as the mean \pm SD of the fold-change with respect to the control. Fold-change $>1$ and fold-change $<1$ represent upregulation and downregulation, respectively. n=5. miRNA/miR, microRNA; ACSL1, long-chain-fatty-acid-CoA ligase 1; NAMPT, nicotinamide phosphoribosyltransferase; RGS2, regulator of G-protein signaling 2; JDP2, Jun dimerization protein 2 .

$\left.\mathrm{P}=1.3 \times 10^{-05}\right)$, AQP9 $\left(\mathrm{P}=9 \times 10^{-12} ; \mathrm{P}<2.22 \times 10^{-16} ; \mathrm{P}<2.22 \times 10^{-16}\right)$ and JDP2 $\left(\mathrm{P}=0.00031 ; \mathrm{P}=1.3 \times 10^{-08} ; \mathrm{P}=1.3 \times 10^{-07}\right)$ in MI were significantly downregulated at discharge, one month after discharge and six months after discharge compared with that at admission. Whereas, it was found that the expression levels of STAT1 $\left(\mathrm{P}=8.1 \times 10^{-11} ; \mathrm{P}=2.1 \times 10^{-13} ; \mathrm{P}=7 \times 10^{-10}\right)$ and AKT3 $\left(\mathrm{P}=0.0036 ; \mathrm{P}=5.6 \times 10^{-06} ; \mathrm{P}=1 \times 10^{-09}\right)$ in $\mathrm{MI}$ were significantly upregulated at discharge, one month after discharge and six months after discharge compared with that at admission. This suggested that ACSL1, NAMPT, RGS2, AQP9, JDP2, STAT1 and AKT3 expression could be used to monitor the recurrence risk of patients with MI.

Diagnosis prediction of differentially expressed target mRNAs associated with prognosis. ROC curve analysis was performed to assess the diagnostic ability of ACSL1, NAMPT, RGS2, AQP9, JDP2, STAT1 and AKT3 (Fig. 8). Of note, AUC values of the aforementioned differentially expressed target mRNAs were all $>0.6$, suggesting that they have a potential diagnostic value for MI.

$R T-q P C R$. A total of five patients with MI and five normal controls were included in the present study. Clinical information of these individuals is presented in Table IV. In addition, three differentially expressed miRNAs (hsa-miR-142-3p, hsa-miR-15a-3p and hsa-miR-33b-5p) and their target mRNAs (ACSL1, NAMPT, RGS2 and JDP2) were randomly selected for validation via RT-qPCR (Fig. 9). The relative expression levels of hsa-miR-142-3p, hsa-miR-15a-3p and hsa-miR-33b-5p were downregulated in the blood of patients with MI. The 


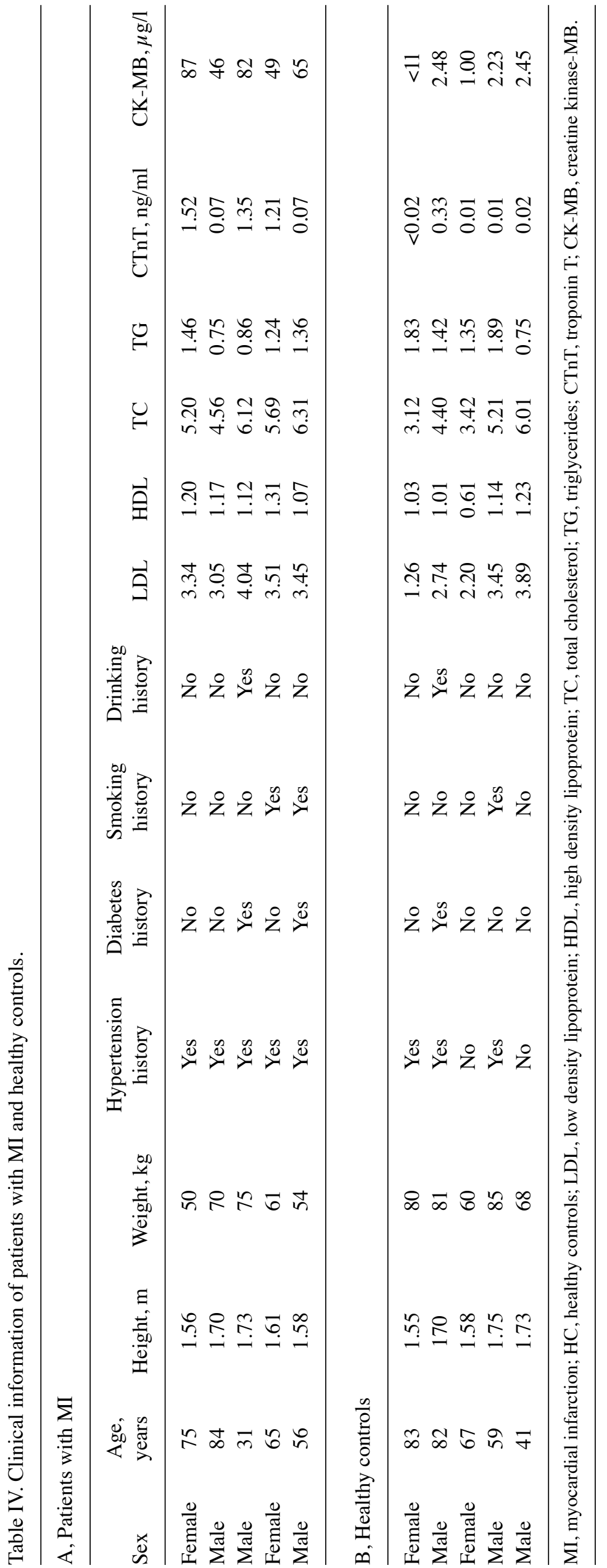


relative expression levels of ACSL1, NAMPT, RGS2 and JDP2 were upregulated in the blood of patients with MI. These results were consistent with the bioinformatics analysis.

\section{Discussion}

Decreased expression of hsa-miR-142-3p was found in patients with heart failure (34). Su et al (35) demonstrated that upregulating hsa-miR-142-3p could ameliorate myocardial ischemic injury. Of note, hsa-miR-142-3p is considered to be a biomarker for acute MI (36). In the present study, it was found that hsa-miR-142-3p was downregulated in the blood of patients with MI. Additionally, ACSL1 was found to be one of the target mRNAs of hsa-miR-142-3p and the most upregulated gene. Moreover, ACSL1 was shown to have a diagnostic and prognostic value for patients with MI. ACSL1 catalyzes the synthesis of acyl-CoA from fatty acid synthase (37). Overexpression of ACSL1 can lead to severe cardiomyopathy (38). The expression of ACSL1 is significantly related to the degree of atherosclerosis in the coronary artery (39). It has been observed that ACSL1 is upregulated in peripheral blood leukocytes of patients with acute MI (39). The present study further demonstrated the important roles of hsa-miR-142-3p and ACSL1 in MI.

Mature hsa-miR-15a-3p influences vascular function, including the expression of vascular endothelial growth factor receptor 2 (40-43). hsa-miR-15a-3p is notably downregulated in the atrial myocardial tissue of patients with congenital heart defect (44). The present study found decreased expression of hsa-miR-15a-3p in the blood of patients with MI; NAMPT was shown to be regulated by hsa-miR-15a-3p. Furthermore, NAMPT could be regarded as a diagnostic and prognostic biomarker for patients with MI. NAMPT is involved in atherosclerosis and myocardial failure (45). Increased expression of NAMPT has been found in MI (46). In addition, FK866 (a specific inhibitor of NAMPT) reduced infarct size following MI (47). The present results suggested that hsa-miR-15a-3p may play a critical role in the process of MI by targeting NAMPT.

Upregulation of hsa-miR-17-3p was demonstrated to promote the viability of cardiomyocytes (48). Overexpression of hsa-miR-17-3p can inhibit fibrosis of cardiac fibroblasts (49). In addition, hsa-miR-17-3p is related to atherosclerosis and angiogenesis (50-52). In the present study, it was found that hsa-miR-17-3p was downregulated in the blood of patients with MI. In addition, JDP2 was shown to be the target of hsa-miR-17-3p. It is worth mentioning that JDP2 was associated with diagnosis and prognosis. The expression of JDP2 was revealed to be increased in patients with heart failure and MI $(46,53)$. Of note, JDP2 is considered to be a candidate marker for the risk stratification of patients who may develop heart failure following MI (54). The present results indicated that JDP2 may be involved in the development of MI under the regulation of hsa-miR-17-3p.

hsa-miR-33b-5p is a hypoxia-regulated miRNA. The methylation level of the encoding region of hsa-miR-33b-5p is related to lipid levels (55). The present study found that hsa-miR-33b-5p was downregulated in the blood of patients with MI. Moreover, upregulated RGS2 with diagnostic and prognostic value was shown to be regulated by hsa-miR-33b-5p.
RGS2 is involved in regulating vascular smooth muscle cell contraction and blood pressure $(56,57)$. Dysfunction of RGS2 is associated with cardiac hypertrophy (58). The present results suggested that hsa-miR-33b-5p could be associated with MI pathology by targeting RGS2.

A previous report found that hsa-miR-24-1-5p reduced cardiac fibrosis following MI (59). In the current study, decreased expression of hsa-miR-24-1-5p was found in the blood of patients with MI. In addition, upregulated AQP9 was one of the targets of hsa-miR-24-1-5p. Moreover, AQP9 had a diagnostic and prognostic value for patients with MI. It has been reported that increased AQP9 is associated with the development of atherosclerotic lesions (60). It has been demonstrated that AQP9 is notably upregulated in patients with heart failure and MI $(46,61)$. In addition, silencing of the AQP9 gene was revealed to inhibit apoptosis of myocardial cells and improve cardiac function following MI (62). Thus, it has been demonstrated that hsa-miR-24-1-5p and AQP9 may play a significant role in cardiac function following MI.

has-miR-34a-5p, which is associated with cardiac fibrosis and regeneration, is upregulated during atherosclerosis progression $(63,64)$. Increased expression of hsa-miR-34a-5p in circulation is related to cardiac remodeling and heart failure following MI (65-67). In the present study, it was found that hsa-miR-34a-5p was upregulated in the blood of patients with MI. In addition, downregulation of STAT1 and AKT3 was shown to be regulated by hsa-miR-34a-5p. Furthermore, STAT1 and AKT3 were associated with the diagnosis and prognosis of patients with MI. Activation of STAT1 has been demonstrated to induce cardiomyocyte apoptosis following ischemia/reperfusion injury by enhancing the expression of pro-apoptotic proteins, which suggests that STAT1 plays a key role in the pathology of MI (68-70). AKT3 is involved in cardiomyocyte cell death (71). In rats, the expression of AKT3 is decreased in the spinal cord following myocardial ischemia-reperfusion injury (72). In addition, AKT3 deficiency is related to an increase in atherosclerosis (73).

A side from being a target of has-miR-34a-5p, it was also found that STAT1 was involved in the "chemokine signaling pathway' and 'Jak-STAT signaling pathway' according to KEGG. AKT3 was found to be involved in the 'MAPK signaling pathway' and ' $T$ cell receptor signaling pathway' according to KEGG. Previous studies revealed that chemokines were expressed in the infarcted myocardium and play an important role in myocardial inflammation and healing $(74,75)$. The Jak/STAT signaling pathway plays a key role in the modulation of cardioprotection against ischemia/reperfusion injury $(76,77)$. Activation of p38 MAPK has been observed in cardiac hypertrophy induced by MI, and inhibition of the signing pathway protects the heart against MI (78). In addition, the p38-JNK-MAPK signaling pathway is associated with the inflammatory response in MI (79-81). $\mathrm{T}$ cells, the main components of cell-mediated inflammation, are associated with the development of atherosclerotic plaques (82). Notably, Abbate et al (83) detected activated $\mathrm{T}$ cells in the infarct and remote areas of the heart tissue of patients with MI.

In conclusion, the bioinformatics analysis from the GEO database led to the finding of several potential differentially 
expressed miRNAs and mRNAs. The epigenetic modifications of hsa-miR-142-2p-ACSL1, hsa-miR-15a-3p-NAMPT, hsa-miR-17-3p-JDP2, hsa-miR-33-5p-RGS2, hsa-miR24-1-5p-AQP9 and hsa-miR-34a-5p-STAT1/AKT3 and four signaling pathways ('chemokine signaling pathway', 'Jak-STAT signaling pathway', 'MAPK signaling pathway' and ' $T$ cell receptor signaling pathway') may be associated with the development of MI. In addition, ACSL1, NAMPT, RGS2, JDP2, AQP9, STAT1 and AKT3 could monitor the recurrence risk of patients with MI. However, there is a limitation of the present study. The underlying mechanism of the identified differentially expressed miRNAs and mRNAs in MI requires further study in vivo and in vitro.

\section{Acknowledgements}

Not applicable.

\section{Funding}

No funding was received.

\section{Availability of data and materials}

The datasets generated and/or analyzed during the current study are available in the GEO repository under accession nos. GSE24548 (https://www.ncbi.nlm.nih.gov/geo/query/ acc.cgi?acc=GSE24548), GSE97320 (https://www.ncbi.nlm. nih.gov/geo/query/acc.cgi?acc=GSE97320), GSE24519 (https:// www.ncbi.nlm.nih.gov/geo/query/acc.cgi?acc=GSE24519), GSE66360 (https://www.ncbi.nlm.nih.gov/geo/query/acc. cgi?acc=GSE66360) and GSE60993 (https://www.ncbi.nlm.nih. gov/geo/query/acc.cgi?acc=GSE60993).

\section{Authors' contributions}

SW drafted the manuscript. SW and NC carried out the experiments and analyzed and interpreted the data. SW designed the study. All authors read and approved the final manuscript.

\section{Ethics approval and consent to participate}

Ethics approval was obtained from the Ethics Committee of Jinan Jigang Hospital (approval no. JG-001) and informed written consent was obtained from all individuals.

\section{Patient consent for publication}

Not applicable.

\section{Competing interests}

The authors declare that they have no competing interests.

\section{References}

1. Bainey KR, Fresco C, Zheng Y, Halvorsen S, Carvalho A, Ostojic M, Goldstein P, Gershlick AH, Westerhout CM, Van de Werf $\mathrm{F}$, et al: Implications of ischaemic area at risk and mode of reperfusion in ST-elevation myocardial infarction. Heart 102: 527-533, 2016
2. Goto Y, Masaki I, Yamada A, Uno M, Nakamori S, Nagata M, Ichikawa Y, Kitagawa K, Ito M and Sakuma H: Native T1 mapping allows for the accurate detection of the segments with chronic myocardial infarction in patients with known or suspected coronary artery disease. J Cardiovasc Magn Reson 18: P70, 2016.

3. Orlic D, Ostojic M,Beleslin B, Milasinovic D, Tesic M, Borovic M, Vukcevic V, Stojkovic S, Nedeljkovic M and Stankovic G: The randomized physiologic assessment of thrombus aspiration in patients with acute ST-segment elevation myocardial infarction trial (PATA STEMI): Study rationale and design. J Interv Cardiol 27: 341-347, 2014

4. Furtado MB, Costa MW and Rosenthal NA: The cardiac fibroblast: Origin, identity and role in homeostasis and disease. Differentiation 92: 93-101, 2016.

5. Kurose $\mathrm{H}$ and Mangmool S: Myofibroblasts and inflammatory cells as players of cardiac fibrosis. Arch Pharm Res 39: 1100-1113, 2016.

6. Gao $M$, Yin D, Chen $J$ and $Q u$ X: Activating the interleukin-6-Gp130-STAT3 pathway ameliorates ventricular electrical stability in myocardial infarction rats by modulating neurotransmitters in the paraventricular nucleus. BMC Cardiovasc Disord 20: 60, 2020.

7. Ouweneel DM, Eriksen E, Sjauw KD, van Dongen IM, Hirsch A, Packer EJ, Vis MM, Wykrzykowska JJ, Koch KT, Baan J, et al: Percutaneous mechanical circulatory support versus intra-aortic balloon pump in cardiogenic shock after acute myocardial infarction. J Am Coll Cardiol 69: 278-287, 2017.

8. Rodríguez-Jiménez AE, Cruz-Inerarity H, Negrín-Valdés T, Fardales-Rodríguez R and Chávez-González E: Corrected QT-Interval Dispersion: An Electrocardiographic Tool to Predict Recurrence of Myocardial Infarction. MEDICC Rev 21: 22-25, 2019.

9. Frangogiannis NG, Smith CW and Entman ML: The inflammatory response in myocardial infarction. Cardiovasc Res 53: 31-47, 2002.

10. Nian M, Lee P, Khaper N and Liu P: Inflammatory cytokines and postmyocardial infarction remodeling. Circ Res 94: 1543-1553, 2004.

11. Landmesser U, Wollert KC and Drexler H: Potential novel pharmacological therapies for myocardial remodelling. Cardiovase Res 81: 519-527, 2009.

12. Yamada Y, Ichihara S and Nishida T: Molecular genetics of myocardial infarction. Genomic Med 2: 7-22, 2008.

13. Swirski FK and Nahrendorf M: Leukocyte behavior in atherosclerosis, myocardial infarction, and heart failure. Science 339: 161-166, 2013.

14. Cheng Y and Zhang C: MicroRNA-21 in cardiovascular disease. J Cardiovasc Transl Res 3: 251-255, 2010.

15. Marques FZ, Vizi D, Khammy O, Mariani JA and Kaye DM: The transcardiac gradient of cardio-microRNAs in the failing heart. Eur J Heart Fail 18: 1000-1008, 2016.

16. Oliveira-Carvalho V, da Silva MM, Guimarães GV, Bacal F and Bocchi EA: MicroRNAs: new players in heart failure. Mol Biol Rep 40: 2663-2670, 2013.

17. Huang JB, Mei J, Jiang LY, Jiang ZL, Liu H, Zhang JW and Ding FB: miR-196a2 rs11614913 T $>$ C polymorphism is associated with an increased risk of tetralogy of fallot in a Chinese population. Acta Cardiol Sin 31: 18-23, 2015.

18. Meder B, Keller A, Vogel B, Haas J, Sedaghat-Hamedani F, Kayvanpour E, Just S, Borries A, Rudloff J, Leidinger P, et al: MicroRNA signatures in total peripheral blood as novel biomarkers for acute myocardial infarction. Basic Res Cardiol 106: 13-23, 2011.

19. Bostjancic E, Zidar N and Glavac D: MicroRNA microarray expression profiling in human myocardial infarction. Dis Markers 27: 255-268, 2009.

20. Liang H, Zhang C, Ban T, Liu Y, Mei L, Piao X, Zhao D, Lu Y, Chu W and Yang B: A novel reciprocal loop between microRNA-21 and TGF $\beta$ RIII is involved in cardiac fibrosis. Int $\mathrm{J}$ Biochem Cell Biol 44: 2152-2160, 2012.

21. Shan ZX, Lin QX, Fu YH, Deng CY, Zhou ZL, Zhu JN, Liu XY, Zhang YY, Li Y, Lin SG and Yu XY: Upregulated expression of $\mathrm{miR}-1 / \mathrm{miR}-206$ in a rat model of myocardial infarction. Biochem Biophys Res Commun 381: 597-601, 2009.

22. Shi B, Guo Y, Wang J and Gao W: Altered expression of microRNAs in the myocardium of rats with acute myocardial infarction. BMC Cardiovasc Disord 10: 11, 2010.

23. Ritchie ME, Phipson B, Wu D, Hu Y, Law CW, Shi W and Smyth GK: limma powers differential expression analyses for RNA-sequencing and microarray studies. Nucleic Acids Res 43: e47, 2015 
24. Marot G, Foulley JL, Mayer CD and Jaffrézic F: Moderated effect size and P-value combinations for microarray meta-analyses. Bioinformatics 25: 2692-2699, 2009.

25. Reiner-Benaim A: FDR control by the BH procedure for two-sided correlated tests with implications to gene expression data analysis. Biom J 49: 107-126, 2007.

26. Benjamini Y and Hochberg Y: Controlling the false discovery rate: A practical and powerful approach to multiple testing. J R Stat Soc Series B Stat Methodol 57: 289-300, 1995.

27. Wu Y, Zhang L, Zhang Y, Zhen Y and Liu S: Bioinformatics analysis to screen for critical genes between survived and non-survived patients with sepsis. Mol Med Rep 18: 3737-3743, 2018.

28. Shannon P, Markiel A, Ozier O, Baliga NS, Wang JT, Ramage D, Amin N, Schwikowski B and Ideker T: Cytoscape: A software environment for integrated models of biomolecular interaction networks. Genome Res 13: 2498-2504, 2003.

29. Ashburner M, Ball CA, Blake JA, Botstein D, Butler H, Cherry JM, Davis AP, Dolinski K, Dwight SS, Eppig JT, et al: Gene ontology: Tool for the unification of biology. The Gene Ontology Consortium. Nat Genet 25: 25-29, 2000.

30. The Gene Ontology Consortium: The Gene Ontology Resource: 20 years and still GOing strong. Nucleic Acids Res 47: D330-D338, 2019.

31. Kanehisa M and Goto S: KEGG: kyoto encyclopedia of genes and genomes. Nucleic Acids Res 28: 27-30, 2000.

32. Robin X, Turck N, Hainard A, Tiberti N, Lisacek F, Sanchez JC and Müller M: pROC: An open-source package for R and S+ to analyze and compare ROC curves. BMC Bioinformatics 12: 77, 2011.

33. Livak KJ and Schmittgen TD: Analysis of relative gene expression data using real-time quantitative PCR and the 2(-Delta Delta C(T)) method. Methods 25: 402-408, 2001

34. Ellis KL, Cameron VA, Troughton RW, Frampton CM, Ellmers LJ and Richards AM: Circulating microRNAs as candidate markers to distinguish heart failure in breathless patients. Eur J Heart Fail 15: 1138-1147, 2013.

35. Su Q, Liu Y, Lv XW, Ye ZL, Sun YH, Kong BH and Qin ZB: Inhibition of lncR NA TUG1 upregulates miR-142-3p to ameliorate myocardial injury during ischemia and reperfusion via targeting HMGB1- and Rac1-induced autophagy. Mol Cell Cardiol 133: 12-25, 2019.

36. Zhu Y, Lin Y, Yan W, Sun Z, Jiang Z, Shen B, Jiang X and Shi J: Novel biomarker MicroRNAs for subtyping of acute coronary syndrome: A Bioinformatics Approach. Biomed Res Int 2016 4618323, 2016

37. Durgan DJ, Smith JK, Hotze MA, Egbejimi O, Cuthbert KD, Zaha VG, Dyck JR, Abel ED and Young ME: Distinct transcriptional regulation of long-chain acyl-CoA synthetase isoforms and cytosolic thioesterase 1 in the rodent heart by fatty acids and insulin. Am J Physiol Heart Circ Physiol 290: H2480-H2497, 2006.

38. Chiu HC, Kovacs A, Ford DA, Hsu FF, Garcia R, Herrero P, Saffitz JE and Schaffer JE: A novel mouse model of lipotoxic cardiomyopathy. J Clin Invest 107: 813-822, 2001.

39. Yang L, Yang Y, Si D, Shi K, Liu D, Meng H and Meng F: High expression of long chain acyl-coenzyme A synthetase 1 in peripheral blood may be a molecular marker for assessing the risk of acute myocardial infarction. Exp Ther Med 14: 4065-4072, 2017

40. Sun CY, She XM, Qin Y, Chu ZB, Chen L, Ai LS, Zhang L and $\mathrm{Hu} \mathrm{Y}$ : miR-15a and miR-16 affect the angiogenesis of multiple myeloma by targeting VEGF. Carcinogenesis 34: 426-435, 2013.

41. Jackstadt R and Hermeking H: MicroRNAs as regulators and mediators of c-MYC function. Biochim Biophys Acta 1849: 544-553, 2015.

42. Chamorro-Jorganes A, Araldi E, Penalva LO, Sandhu D Fernández-Hernando $\mathrm{C}$ and Suárez Y: MicroRNA-16 and microRNA-424 regulate cell-autonomous angiogenic functions in endothelial cells via targeting vascular endothelial growth factor receptor-2 and fibroblast growth factor receptor-1. Arterioscler Thromb Vasc Biol 31: 2595-2606, 2011.

43. Chan LS, Yue PY, Wong YY and Wong RN: MicroRNA-15b contributes to ginsenoside-Rg1-induced angiogenesis through increased expression of VEGFR-2. Biochem Pharmacol 86: 392-400, 2013.

44. Abu-Halima M, Poryo M, Ludwig N, Mark J, Marsollek I, Giebels C, Petersen J, Schäfers HJ, Grundmann U, Pickardt T, et al: Differential expression of microRNAs following cardiopulmonary bypass in children with congenital heart diseases. J Transl Med 15: 117, 2017.
45. Dahl TB, Holm S, Aukrust P and Halvorsen B: Visfatin/NAMPT: A multifaceted molecule with diverse roles in physiology and pathophysiology. Annu Rev Nutr 32: 229-243, 2012.

46. Qiu L and Liu X: Identification of key genes involved in myocardial infarction. Eur J Med Res 24: 22, 2019.

47. Montecucco F, Bauer I, Braunersreuther V, Bruzzone S, Akhmedov A, Lüscher TF, Speer T, Poggi A, Mannino E, Pelli G, et al: Inhibition of nicotinamide phosphoribosyltransferase reduces neutrophil-mediated injury in myocardial infarction. Antioxid Redox Signal 18: 630-641, 2013.

48. Wang $X$, Chen $\mathbf{J}$ and Huang $X$ : Rosuvastatin attenuates myocardial ischemia-reperfusion injury via upregulating miR-17-3p-mediated autophagy. Cell Reprogram 21: 323-330, 2019.

49. Tao H, Chen ZW, Yang JJ and Shi KH: MicroRNA-29a suppresses cardiac fibroblasts proliferation via targeting VEGF-A/MAPK signal pathway. Int J Biol Macromol 88: 414-423, 2016.

50. Romaine SP, Tomaszewski M, Condorelli G and Samani NJ: MicroRNAs in cardiovascular disease: An introduction for clinicians. Heart 101: 921-928, 2015.

51. Dews M, Homayouni A, Yu D, Murphy D, Sevignani C, Wentzel E, Furth EE, Lee WM, Enders GH, Mendell JT and Thomas-Tikhonenko A: Augmentation of tumor angiogenesis by a Myc-activated microRNA cluster. Nat Genet 38: 1060-1065, 2006.

52. Landskroner-Eiger S, Qiu C, Perrotta P, Siragusa M, Lee MY, Ulrich V, Luciano AK, Zhuang ZW, Corti F, Simons M, et al: Endothelial miR-17 92 cluster negatively regulates arteriogenesis via miRNA-19 repression of WNT signaling. Proc Natl Acad Sci USA 112: 12812-12817, 2015.

53. Maciejak A, Kiliszek M, Michalak M, Tulacz D, Opolski G, Matlak K, Dobrzycki S, Segiet A, Gora M and Burzynska B: Gene expression profiling reveals potential prognostic biomarkers associated with the progression of heart failure. Genome Med 7: $26,2015$.

54. Heger J, Bornbaum J, Würfel A, Hill C, Brockmann N, Gáspár R, Pálóczi J, Varga ZV, Sárközy M, Bencsik P, et al: JDP2 overexpression provokes cardiac dysfunction in mice. Sci Rep 8: 7647, 2018.

55. Pfeiffer L, Wahl S, Pilling LC, Reischl E, Sandling JK, Kunze S, Holdt LM, Kretschmer A, Schramm K, Adamski J, et al: DNA methylation of lipid-related genes affects blood lipid levels. Circ Cardiovasc Genet 8: 334-342, 2015.

56. Heximer SP, Knutsen RH, Sun X, Kaltenbronn KM, Rhee MH, Peng N, Oliveira-dos-Santos A, Penninger JM, Muslin AJ, Steinberg TH, et al: Hypertension and prolonged vasoconstrictor signaling in RGS2-deficient mice. J Clin Invest 111: 445-452, 2003.

57. Tang KM, Wang GR, Lu P, Karas RH, Aronovitz M, Heximer SP, Kaltenbronn KM, Blumer KJ, Siderovski DP, Zhu Y and Mendelsohn ME: Regulator of G-protein signaling-2 mediates vascular smooth muscle relaxation and blood pressure. Nat Med 9: 1506-1512, 2003.

58. Wieland T, Lutz S and Chidiac P: Regulators of G protein signalling: A spotlight on emerging functions in the cardiovascular system. Curr Opin Pharmacol 7: 201-207, 2007.

59. Wang J, Huang W, Xu R, Nie Y, Cao X, Meng J, Xu X, Hu S and Zheng Z: MicroRNA-24 regulates cardiac fibrosis after myocardial infarction. J Cell Mol Med 16: 2150-2160, 2012.

60. Inouye M, Ripatti S, Kettunen J, Lyytikäinen LP, Oksala N, Laurila PP, Kangas AJ, Soininen P, Savolainen MJ, Viikari J, et al: Novel Loci for metabolic networks and multi-tissue expression studies reveal genes for atherosclerosis. PLoS Genet 8: e1002907, 2012.

61. Thuny F, Textoris J, Amara AB, Filali AE, Capo C, Habib G, Raoult D and Mege JL: The gene expression analysis of blood reveals S100A11 and AQP9 as potential biomarkers of infective endocarditis. PLoS One 7: e31490, 2012.

62. Huang X, Yu X, Li H, Han L and Yang X: Regulation mechanism of aquaporin 9 gene on inflammatory response and cardiac function in rats with myocardial infarction through extracellular signal-regulated kinase1/2 pathway. Heart Vessels 34: 2041-2051, 2019.

63. Yang Y, Cheng HW, Qiu Y, Dupee D, Noonan M, Lin YD, Fisch S, Unno K, Sereti KI and Liao R: MicroRNA-34a plays a key role in cardiac repair and regeneration following myocardial infarction. Circ Res 117: 450-459, 2015.

64. Huang Y, Qi Y, Du JQ and Zhang DF: MicroRNA-34a regulates cardiac fibrosis after myocardial infarction by targeting Smad4. Expert Opin Ther Targets 18: 1355-1365, 2014. 
65. Matsumoto S, Sakata Y, Suna S, Nakatani D, Usami M, Hara M Kitamura T, Hamasaki T, Nanto S, Kawahara Y and Komuro I: Circulating $\mathrm{p} 53$-responsive microRNAs are predictive indicators of heart failure after acute myocardial infarction. Circ Res 113: 322-326, 2013.

66. Bernardo BC, Gao XM, Winbanks CE, Boey EJ, Tham YK, Kiriazis H, Gregorevic P, Obad S, Kauppinen S, Du XJ, et al: Therapeutic inhibition of the miR-34 family attenuates pathological cardiac remodeling and improves heart function. Proc Natl Acad Sci USA 109: 17615-17620, 2012.

67. Bernardo BC, Gao XM, Tham YK, Kiriazis H, Winbanks CE, Ooi JY, Boey EJ, Obad S, Kauppinen S, Gregorevic P, et al: Silencing of miR-34a attenuates cardiac dysfunction in a setting of moderate, but not severe, hypertrophic cardiomyopathy. PLoS One 9: e90337, 2014.

68. Stephanou A, Brar BK, Scarabelli TM, Jonassen AK, Yellon DM Marber MS, Knight RA and Latchman DS: Ischemia-induced STAT-1 expression and activation play a critical role in cardiomyocyte apoptosis. J Biol Chem 275: 10002-10008, 2000.

69. Stephanou A: Role of STAT-1 and STAT-3 in ischaemia/reperfusion injury. J Cell Mol Med 8: 519-525, 2004.

70. Zhang S, Liu W, Liu X, Qi J and Deng C: Biomarkers identification for acute myocardial infarction detection via weighted gene co-expression network analysis. Medicine (Baltimore) 96: e8375, 2017.

71. Chang PC, Lin SF, Chu Y, Wo HT, Lee HL, Huang YC, Wen MS and Chou CC: LCZ696 therapy reduces ventricular tachyarrhythmia inducibility in a myocardial infarction-induced heart failure rat model. Cardiovasc Ther 2019: 6032631, 2019.

72. Li SY, Li ZX, He ZG, Wang Q, Li YJ, Yang Q, Wu DZ, Zeng HL and Xiang HB: Quantitative proteomics reveal the alterations in the spinal cord after myocardial ischemia-reperfusion injury in rats. Int J Mol Med 44: 1877-1887, 2019.

73. Getz GS and Reardon CA: Do the Apoe ${ }^{-1}$ - and $\mathrm{Ldll}^{-1}$ Mice yield the same insight on atherogenesis? Arterioscler Thromb Vasc Biol 36: 1734-1741, 2016.

74. Frangogiannis NG: Chemokines in the ischemic myocardium: From inflammation to fibrosis. Inflamm Res 53: 585-595, 2004.

75. Frangogiannis NG and Entman ML: Chemokines in myocardial ischemia. Trends Cardiovasc Med 15: 163-169, 2005.

76. Boengler K, Hilfiker-Kleiner D, Drexler H, Heusch G and Schulz R: The myocardial JAK/STAT pathway: From protection to failure. Pharmacol Ther 120: 172-185, 2008 .

77. Fuglesteg BN, Suleman N, Tiron C, Kanhema T, Lacerda L, Andreasen TV, Sack MN, Jonassen AK, Mjøs OD, Opie LH and Lecour S: Signal transducer and activator of transcription 3 is involved in the cardioprotective signalling pathway activated by insulin therapy at reperfusion. Basic Res Cardiol 103: 444-453, 2008 .
78. Liu YH, Wang D, Rhaleb NE, Yang XP, Xu J, Sankey SS, Rudolph AE and Carretero OA: Inhibition of p38 mitogen-activated protein kinase protects the heart against cardiac remodeling in mice with heart failure resulting from myocardial infarction. J Card Fail 11: 74-81, 2005.

79. Ge ZW, Zhu XL, Wang BC, Hu JL, Sun JJ, Wang S, Chen XJ, Meng SP, Liu L and Cheng ZY: MicroRNA-26b relieves inflammatory response and myocardial remodeling of mice with myocardial infarction by suppression of MAPK pathway through binding to PTGS2. Int J Cardiol 280: 152-159, 2019.

80. Liu X, Chen K, Zhuang Y, Huang Y, Sui Y, Zhang Y, Lv L and Zhang G: Paeoniflorin improves pressure overload-induced cardiac remodeling by modulating the MAPK signaling pathway in spontaneously hypertensive rats. Biomed Pharmacother 111: 695-704, 2019.

81. Li C, Li J, Xue K, Zhang J, Wang C, Zhang Q, Chen X, Gao C, Yu X and Sun L: MicroRNA-143-3p promotes human cardiac fibrosis via targeting sprouty 3 after myocardial infarction. J Mol Cell Cardiol 129: 281-292, 2019.

82. Jia L, Zhu L, Wang JZ, Wang XJ, Chen JZ, Song L, Wu YJ, Sun K, Yuan ZY and Hui R: Methylation of FOXP3 in regulatory $\mathrm{T}$ cells is related to the severity of coronary artery disease. Atherosclerosis 228: 346-352, 2013.

83. Abbate A,BonannoE, Mauriello A,Bussani R,Biondi-ZoccaiGG, Liuzzo G, Leone AM, Silvestri F, Dobrina A, Baldi F, et al: Widespread myocardial inflammation and infarct-related artery patency. Circulation 110: 46-50, 2004.

84. Fan L, Meng H, Guo X, Li X and Meng F: Differential gene expression profiles in peripheral blood in northeast chinese han people with acute myocardial infarction. Genet Mol Biol 41: 59-66, 2018.

85. Muse ED, Kramer ER, Wang H, Barrett P, Parviz F, Novotny MA, Lasken RS, Jatkoe TA, Oliveira G, Peng H, et al: A whole blood molecular signature for acute myocardial infarction. Sci Rep 7: $12268,2017$.

86. Park HJ, Noh JH, Eun JW, Koh YS, Seo SM, Park WS, Lee JY, Chang K, Seung KB, Kim PJ and Nam SW: Assessment and diagnostic relevance of novel serum biomarkers for early decision of ST-elevation myocardial infarction. Oncotarget 6: 12970-12983, 2015.

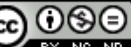

This work is licensed under a Creative Commons Attribution-NonCommercial-NoDerivatives 4.0 International (CC BY-NC-ND 4.0) License. 